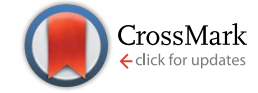

Cite this: RSC Adv., 2016, 6, 5428
Received 14th December 2015 Accepted 5th January 2016

DOI: 10.1039/c5ra26647e

www.rsc.org/advances

\section{Development of a $D-\pi-A$ pyrazinium photosensitizer possessing singlet oxygen generation $\uparrow$}

\begin{abstract}
Yousuke Ooyama, ${ }^{*}$ Toshiaki Enoki and Joji Ohshita*
$(\mathrm{D}-\pi-)_{2} \mathrm{~A}$ pyrazinium dyes (OEJ-1 and OEJ-2) bearing a counter anion $\left(\mathrm{X}^{-}=\mathrm{Br}^{-}\right.$or $\mathrm{I}^{-}$) have been newly developed as a photosensitizer possessing singlet oxygen $\left({ }^{1} \mathrm{O}_{2}\right)$ generation. The two dyes show specific solvatochromism, leading to a large bathochromic shift of the photoabsorption band in halogenated solvents, compared to polar and non-polar solvents. The effects of the counter anion and solvents on the ${ }^{1} \mathrm{O}_{2}$ generation efficiency such as $\Phi_{\Delta}$ and the rate constant $\left(K_{\text {obs }}\right)$ have been investigated. It was revealed that OEJ-2 $\left(\mathrm{X}^{-}=\mathrm{I}^{-}\right)$exhibits a higher ${ }^{1} \mathrm{O}_{2}$ quantum yield $\left(\Phi_{\Delta}\right)$ than OEJ-1 $\left(\mathrm{X}^{-}=\mathrm{Br}^{-}\right)$. This result indicates that the $(D-\pi-)_{2} A$ pyrazinium dyes possess the ability to generate ${ }^{1} \mathrm{O}_{2}$ under visible light irradiation, due to the effective intersystem crossing (ISC) from the singlet excited state of the photosensitizer $\left({ }^{1} \mathrm{~S}^{*}\right)$ to the triplet excited state $\left({ }^{3} \mathrm{~S}^{*}\right)$ by the superior heavy-atom effect of $\mathrm{I}^{-}$ion as the counter anion. Moreover, it was found that THF and dichloromethane are favorable solvents for the $(D-\pi-)_{2} A$ pyrazinium dyes to efficiently generate ${ }^{1} \mathrm{O}_{2}$ compared with the polar solvents such as acetonitrile and DMSO. On the basis of the ${ }^{1} \mathrm{O}_{2}$ quantum yield, the rate constant for ${ }^{1} \mathrm{O}_{2}$ generation, the HOMO and LUMO energy levels of OEJ-1 and OEJ-2, and density functional theory (DFT) calculation, the photoabsorption and ${ }^{1} \mathrm{O}_{2}$ generation properties of the $\mathrm{D}-\pi-\mathrm{A}$ pyrazinium dyes are discussed.
\end{abstract}

\section{Introduction}

Photosensitizers possessing the ability to generate singlet oxygen $\left({ }^{1} \mathrm{O}_{2}\right)$ have received considerable attention in recent years from the viewpoint of not only fundamental study in photochemistry and photophysics, but also their potential applications in photodynamic therapy (PDT). ${ }^{1-4}{ }^{1} \mathrm{O}_{2}$ generally occurs through the following processes: initially the photosensitizer absorbs light $(h \nu)$ to generate the singlet excited state of the photosensitizer $\left({ }^{1} \mathrm{~S}^{*}\right)$, then the photoexcited dye $\left({ }^{1} \mathrm{~S}^{*}\right)$ undergoes intersystem crossing (ISC) to generate the triplet excited state $\left({ }^{3} \mathrm{~S}^{*}\right)$. Subsequent energy transfer from the photoexcited dye $\left({ }^{3} \mathrm{~S}^{*}\right)$ to triplet oxygen $\left({ }^{3} \mathrm{O}_{2}\right)$ produces ${ }^{1} \mathrm{O}_{2}$. Thus, to enhance ISC efficiency is one of the most effective strategies to generate high ${ }^{1} \mathrm{O}_{2}$ quantum yield. For this purpose, many kinds of photosensitizers exhibiting high ${ }^{1} \mathrm{O}_{2}$ generation efficiency for PDT have been developed, including organic dyes such as methylene blue ${ }^{5}$ and rose bengal, ${ }^{6}$ porphyrin dyes, ${ }^{7,8}$ phthalocyanines, ${ }^{9}$ boron dipyrromethene (BODIPY) dyes, ${ }^{\mathbf{1 0 - 1 2}}$ fullerene derivatives ${ }^{13,14}$ and ruthenium $(\mathrm{Ru})^{15}$ and iridium (Ir) complexes, ${ }^{\mathbf{1 6}}$ and the mechanisms of ${ }^{1} \mathrm{O}_{2}$ generation by the

Department of Applied Chemistry, Graduate School of Engineering, Hiroshima University, Higashi-Hiroshima 739-8527, Japan. E-mail: yooyama@hiroshima-u.ac. jp; Fax: +81-82-424-5494

$\dagger$ Electronic supplementary information (ESI) available. See DOI: $10.1039 / \mathrm{c} 5 \mathrm{ra} 26647 \mathrm{e}$ photosensitizers were investigated. ${ }^{\mathbf{1 - 4 , 1 7}}$ However, there have been few efforts to develop new organic photosensitizers possessing the ability to generate ${ }^{1} \mathrm{O}_{2} \cdot{ }^{18}$

Thus, in this work, to gain insight into a direction in molecular design toward creating new photosensitizer family possessing ${ }^{1} \mathrm{O}_{2}$ generation, we have developed $(\mathrm{D}-\pi-)_{2} \mathrm{~A}$ pyrazinium dyes (OEJ-1 and OEJ-2) bearing bromide ion $\left(\mathrm{Br}^{-}\right)$or iodide ion $\left(\mathrm{I}^{-}\right)$as a counter anion (Scheme 1$)$. The heavy atoms such as bromine and iodine would be expected to facilitate ISC by the heavy-atom effect. Moreover, D- $\pi-\mathrm{A}$ pyrazinium dyes have an advantage over the conventional photosensitizers in

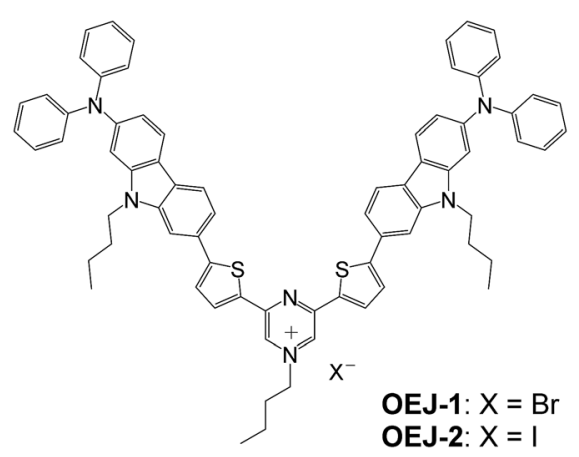

Scheme 1 Chemical structures of (D- $\pi-)_{2} A$ pyrazinium dyes OEJ-1 and OEJ-2. 
carrying out the fundamental study on ${ }^{1} \mathrm{O}_{2}$ generation, that is, we can obtain a great deal of useful knowledge for the relationship between the molecular structures and ${ }^{1} \mathrm{O}_{2}$ generation efficiency, by easily exchanging the counter ion. Interestingly, it was found that the $(\mathrm{D}-\pi-)_{2} \mathrm{~A}$ pyrazinium dyes show specific solvatochromism, leading to a large bathochromic shift of absorption band in halogenated solvents, compared to polar and non-polar solvents. Therefore, the effects of the counter anion and solvents on the ${ }^{1} \mathrm{O}_{2}$ generation efficiency have been investigated. On the basis of ${ }^{1} \mathrm{O}_{2}$ quantum yield $\left(\Phi_{\Delta}\right)$, rate constant $\left(K_{\text {obs }}\right)$ for ${ }^{1} \mathrm{O}_{2}$ generation, the HOMO and LUMO energy levels of OEJ-1 and OEJ-2, and density functional theory (DFT) calculation, the photoabsorption and ${ }^{1} \mathrm{O}_{2}$ generation properties of the $(\mathrm{D}-\pi-)_{2} \mathrm{~A}$ pyrazinium dyes are discussed.

\section{Results and discussion}

\section{Synthesis}

The (D- $\pi-)_{2} \mathrm{~A}$ pyrazinium dyes (OEJ-1 and OEJ-2) were synthesized from the (D- $\pi-)_{2}$ A fluorescent dye OUK-2 (ref. 19) and the corresponding $n$-butyl halide (Scheme 2).

\section{Photoabsorption properties}

The photoabsorption spectra of OEJ-1 and OEJ-2 in various solvents (THF, acetonitrile, DMSO and dichloromethane) are shown in Fig. 1 and their optical data are summarized in Table 1. The two dyes show a broad absorption band $\left(\lambda^{\text {abs }}\right)$ at around 500-700 nm, which is assigned to the intramolecular chargetransfer (ICT) excitation from electron donor moiety (diphenylamino group) to electron acceptor moiety (pyrazinium group). In all the four solvents, the $\lambda^{\text {abs }}$ for ICT band of OEJ-2 occurs at a longer wavelength than of $\mathbf{O E J}-\mathbf{1}$. Interestingly, the two dyes showed the specific solvatochromism as with the previously reported $\mathrm{D}-\pi-\mathrm{A}$ pyridinium dyes, ${ }^{\mathbf{2 0}}$ leading to a large bathochromic shift of absorption band in halogenated solvent such as dichloromethane, compared with that in polar and non-polar solvents; the $\lambda^{\text {abs }}$ for ICT bands of OEJ-1 and OEJ-2 in dichloromethane occurs at a longer wavelength by $c a .30 \mathrm{~nm}$ and $c a .70 \mathrm{~nm}$, respectively, than those in acetonitrile. It is worthy to note here that the specific solvatochromism depends on the counter anion of the $(\mathrm{D}-\pi-)_{2} \mathrm{~A}$ pyrazinium dyes, that is, the bathochromic shifts of ICT band for OEJ-2 bearing $\mathrm{I}^{-}$ion is larger than that of $\mathbf{O E J - 1}$ bearing $\mathrm{Br}^{-}$ion.
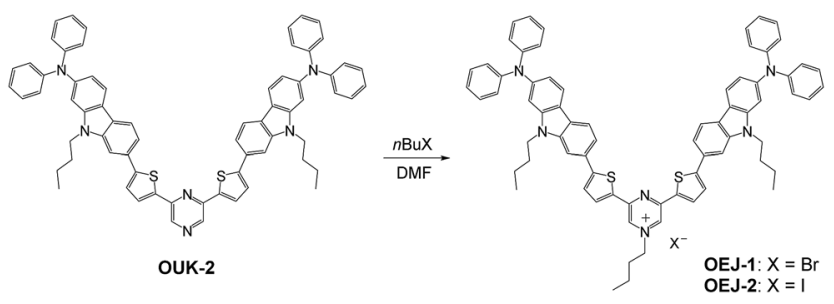

Scheme 2 Synthesis of $(D-\pi-)_{2} A$ pyrazinium dyes OEJ-1 and OEJ-2.
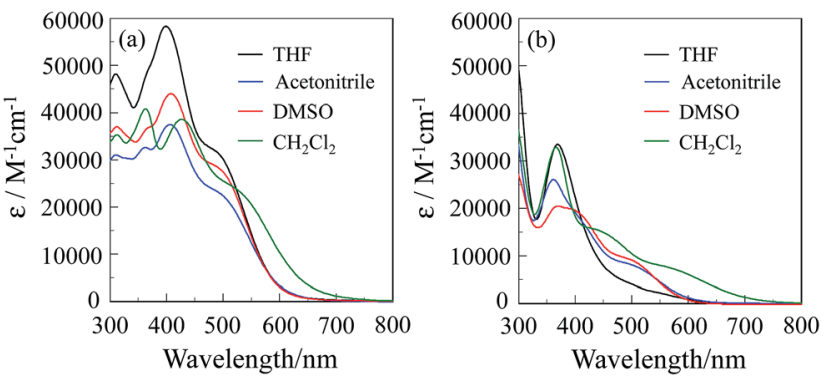

Fig. 1 Photoabsorption spectra of (a) OEJ-1 and (b) OEJ-2 in THF, acetonitrile, DMSO and dichloromethane $\left(\mathrm{CH}_{2} \mathrm{Cl}_{2}\right)$.

\section{Electrochemical properties}

The electrochemical properties of OEJ-1 and OEJ-2 were determined by cyclic voltammetry (CV) in acetonitrile containing 0.1 $\mathrm{M}$ tetrabutylammonium perchlorate $\left(\mathrm{Bu}_{4} \mathrm{NClO}_{4}\right)$. The potentials were referred to ferrocene/ferrocenium $\left(\mathrm{Fc} / \mathrm{Fc}^{+}\right)$as the internal reference (Fig. 2). For OEJ-2, the oxidation wave for the iodide counter ion was observed at around $0.05 \mathrm{~V}$. The oxidation waves were observed at $0.43 \mathrm{~V}$ for $\mathbf{O E J}-1$ and $0.35 \mathrm{~V}$ for $\mathbf{O E J}-2$, respectively, vs. Fc/Fc ${ }^{+}$(Table 1). The corresponding reduction waves appeared at $0.36 \mathrm{~V}$ for $\mathbf{O E J}-1$ and $0.18 \mathrm{~V}$ for $\mathbf{O E J}-2$, respectively. However, the oxidation and corresponding reduction waves are reversible for $\mathbf{O E J - 1}$, but irreversible for $\mathbf{O E J}-2$. In fact, at second cycle OEJ-1 also showed the reversible oxidation wave, but OEJ-2 showed cathodic shift by $c a .0 .1 \mathrm{~V}$ for the oxidation wave as well as disappearance of the oxidation wave for the iodide counter ion (Fig. S3†). The HOMO energy level vs. vacuum level is -5.20 $\mathrm{eV}$ for OEJ-1 and $\mathbf{- 5 . 0 7} \mathrm{eV}$ for $\mathbf{O E J}-\mathbf{2}$, respectively, which was evaluated through equation $-\left[E_{1 / 2}^{\mathrm{ox}}+4.8\right] \mathrm{eV}$ from the half-wave potential for oxidation $\left(E_{1 / 2}^{\mathrm{Ox}}=0.40 \mathrm{~V} v s\right.$. $\mathrm{Fc} / \mathrm{Fc}^{+}$for OEJ-1 and $0.27 \mathrm{~V} v s . \mathrm{Fc} / \mathrm{Fc}^{+}$for OEJ-2). On the other hand, the LUMO energy level is $-3.20 \mathrm{eV}$ for $\mathbf{O E J - 1}$ and $-3.07 \mathrm{eV}$ for $\mathbf{O E J}-2$, respectively, which was estimated from the HOMO and the onset of photoabsorption spectra (620 nm; $2.0 \mathrm{eV}$ for both OEJ-1 and OEJ-2) in acetonitrile.

\section{Theoretical calculations}

In order to examine the HOMO and LUMO of OEJ-1 and OEJ-2, the molecular orbitals of the $(\mathrm{D}-\pi-)_{2} \mathrm{~A}$ pyrazinium dye cation (OEJ) was calculated using density functional theory (DFT) at the B3LYP/6-31G(d,p) level (Fig. 3). ${ }^{21}$ The DFT calculation for the dye cation indicates that the HOMO is mostly localized on the diphenylamine-carbazole moiety containing a thiophene ring. On the other hand, the LUMO is mainly concentrated on pyrazinium moiety. Accordingly, the DFT calculations reveal that excitation of the dye upon light irradiation induces a strong ICT from the diphenylamine-carbazole moiety to the pyrazinium moiety.

\footnotetext{
${ }^{1} \mathrm{O}_{2}$ generation by $(\mathrm{D}-\pi-)_{2} \mathrm{~A}$ pyrazinium dye

${ }^{1} \mathrm{O}_{2}$ generation by (D- $\left.\pi-\right)_{2} \mathrm{~A}$ pyrazinium dyes $\mathbf{O E J}-\mathbf{1}$ and $\mathbf{O E J}-2$ in various solvents (THF, acetonitrile, DMSO and dichloromethane) was evaluated by monitoring the photoabsorption
} 
Table 1 Optical data of OEJ-1 and OEJ-2, and ${ }^{1} \mathrm{O}_{2}$ quantum yield $\left(\Phi_{\Delta}\right)$ and first-order rate constant ( $\left.K_{\text {obs }}\right)$ for the photooxidation of DPBF using OEJ-1 and OEJ-2 as photosensitizer

\begin{tabular}{|c|c|c|c|c|c|}
\hline Dye & Solvent & $\lambda^{\mathrm{abs}} / \mathrm{nm}$ for ICT band & $\varepsilon / \mathrm{M}^{-1} \mathrm{~cm}^{-1} @ \lambda^{\mathrm{abs}}=509 \mathrm{~nm}$ & $\Phi_{\Delta}^{a}$ & $K_{\mathrm{obs}}{ }^{b} / \mathrm{min}^{-1}$ \\
\hline \multirow[t]{3}{*}{ OEJ-1 } & THF & 490 & 28200 & 0.19 & 0.034 \\
\hline & Acetonitrile & 490 & 21200 & $-c$ & $-^{c}$ \\
\hline & Dichloromethane & 520 & 24900 & $-^{c}$ & 0.006 \\
\hline \multirow{2}{*}{ OEJ-2 } & $\mathrm{THF}$ & 500 & 3600 & 0.22 & 0.016 \\
\hline & Acetonitrile & 500 & 7600 & 0.05 & 0.032 \\
\hline
\end{tabular}

${ }^{a}{ }^{1} \mathrm{O}_{2}$ quantum yield (relative decomposition rate of DPBF), with Rose Bengal (RB) as standard $\left(\Phi_{\Delta}=0.80\right.$ in methanol, ${ }^{15}$ see Fig. S4) and $1,3-$ diphenylisobenzofuran (DPBF) as ${ }^{1} \mathrm{O}_{2}$ scavenger. These values were estimated under an assumption that the reactivity of singlet oxygen is independent of the kind of solvents. ${ }^{b}$ First-order rate constant for the reaction of DPBF with ${ }^{1} \mathrm{O}_{2}$ generated upon photoexcitation of OEJ-1 or OEJ-2. The $K_{\mathrm{obs}}$ for RB is $0.250 \mathrm{~min}^{-1}$ (see Fig. S5). ${ }^{c}$ Too low. ${ }^{d}$ Estimated from the slope for the range of 5-10 min in Fig. $9 \mathrm{~b}$.
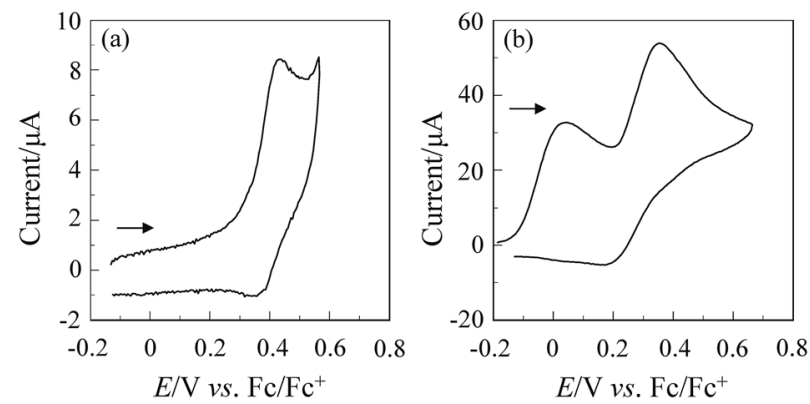

Fig. 2 Cyclic voltammograms of (a) OEJ-1 and (b) OEJ-2 in acetonitrile containing $0.1 \mathrm{M} \mathrm{Bu}_{4} \mathrm{NClO}_{4}$ at the first cycle. The arrow denotes the direction of the potential scan.
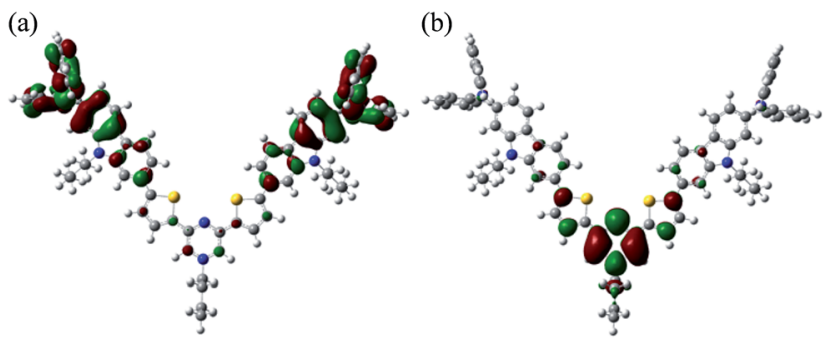

Fig. 3 (a) HOMO and (b) LUMO of OEJ cation by the density functional theory (DFT) calculations at B3LYP/6-31G(d,p) level.

spectral change of the known ${ }^{1} \mathrm{O}_{2}$ scavenger 1,3-diphenylisobenzofuran (DPBF) accompanied by the reaction of DPBF with the generated ${ }^{1} \mathrm{O}_{2}$, that is, DPBF can trap ${ }^{1} \mathrm{O}_{2}$ through its photooxidation. ${ }^{22}$ All the solvents were bubbled with air for 15 min. The air-saturated solution containing the dye (OEJ-1 or OEJ-2) and DPBF was irradiated with $509 \mathrm{~nm}\left(160 \mu \mathrm{W} \mathrm{cm}{ }^{-2}\right.$, see Table 1 for $\varepsilon / \mathrm{M}^{-1} \mathrm{~cm}^{-1} @ \lambda^{\mathrm{abs}}=509 \mathrm{~nm}$ ) obtained by passage of xenon light through monochromator. The absorption band of DPBF at around $410 \mathrm{~nm}$ decreased with the increase in the photoirradiation time (Fig. 4 and 5), which indicate the reaction of DPBF with ${ }^{1} \mathrm{O}_{2}$ generated upon the excitation of $(\mathrm{D}-\pi-)_{2} \mathrm{~A}$ pyrazinium dyes. To gain insight into the effect of the solvent and the counter anion on the efficiency of DPBF photooxidation, the changes in optical density $(\triangle \mathrm{OD})$ of DPBF are plotted against the photoirradiation time (Fig. 6 ), and the slope $\left(m_{\mathrm{sl}}\right)$ is used to estimate the ${ }^{1} \mathrm{O}_{2}$ quantum yield $\left(\Phi_{\Delta}\right)$ for OEJ-1 and OEJ2. It was revealed that the $m_{\mathrm{sl}}$ value for $\mathbf{O E J - 2}$ becomes steeper in the following order: DMSO $\left(-0.4 \times 10^{-3}\right)<$ acetonitrile $(-0.5 \times$ $\left.10^{-3}\right)<$ dichloromethane $\left(-0.8 \times 10^{-3}\right)<$ THF $\left(-2.6 \times 10^{-3}\right)$, that is, the $m_{\mathrm{sl}}$ value in THF is larger than those in the other solvents. It was also found that the $m_{\mathrm{sl}}$ value of OEJ-2 is larger than that of OEJ-1 $\left(-2.0 \times 10^{-3}\right.$ in THF). Consequently, this result indicates that THF is a favorable solvent for the $(\mathrm{D}-\pi-)_{2} \mathrm{~A}$ pyrazinium dyes to present a high DPBF-oxidation efficiency compared with the other solvents. Moreover, the plots demonstrate that $\mathrm{OUJ}-2$ bearing $\mathrm{I}^{-}$ion exhibits higher DPBF-oxidation
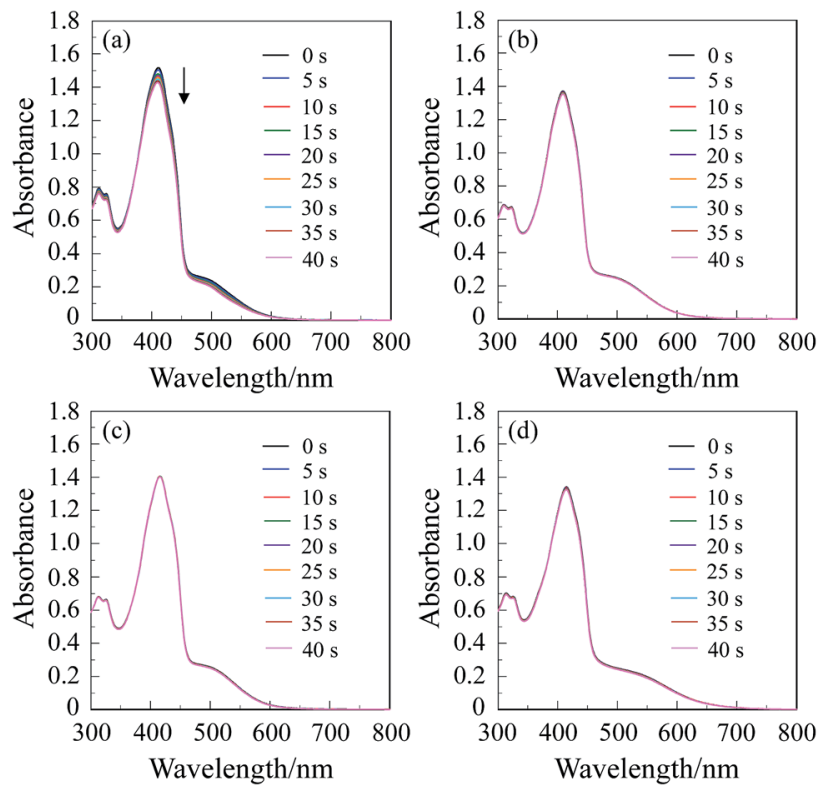

Fig. 4 Photoabsorption spectral changes for the photooxidation of DPBF (4.6 to $\left.5.4 \times 10^{-5} \mathrm{M}\right)$ using OEJ-1 as photosensitizer under photoirradiation with $509 \mathrm{~nm}\left(160 \mu \mathrm{W} \mathrm{cm}^{-2}\right)$ in (a) THF $\left(7.8 \times 10^{-6} \mathrm{M}\right)$, (b) acetonitrile $\left(1.1 \times 10^{-5} \mathrm{M}\right)$, (c) DMSO $\left(9.3 \times 10^{-6} \mathrm{M}\right)$ and (d) dichloromethane $\left(9.7 \times 10^{-6} \mathrm{M}\right)$. 

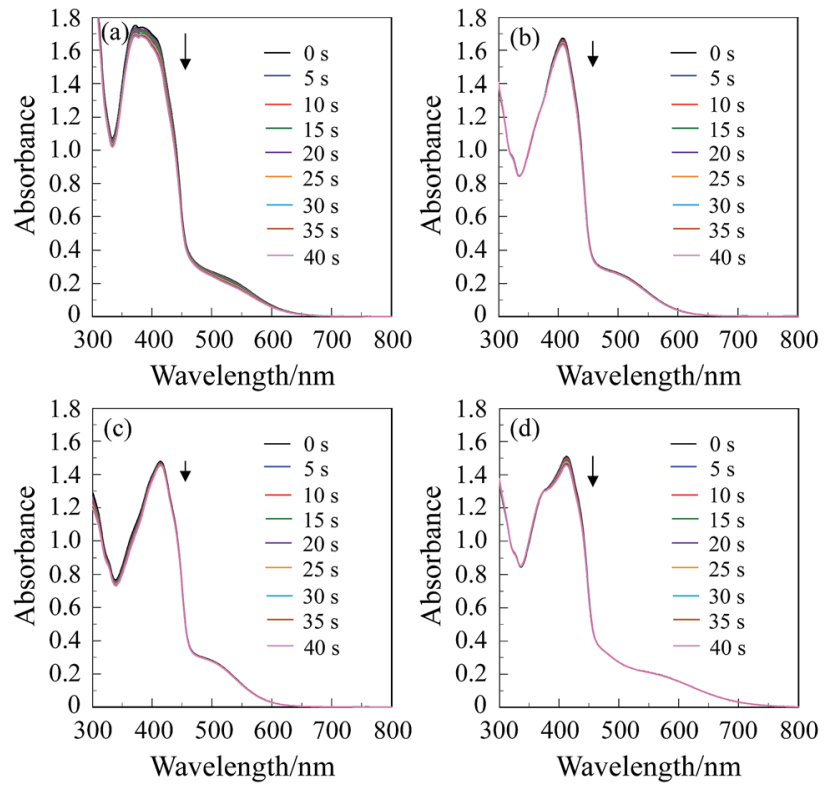

Fig. 5 Photoabsorption spectral changes for the photooxidation of DPBF (2.8 to $\left.6.1 \times 10^{-5} \mathrm{M}\right)$ using OEJ-2 as photosensitizer under photoirradiation with $509 \mathrm{~nm}\left(160 \mu \mathrm{W} \mathrm{cm}^{-2}\right)$ in (a) THF $\left(7.2 \times 10^{-5} \mathrm{M}\right)$, (b) acetonitrile $\left(3.3 \times 10^{-5} \mathrm{M}\right)$, (c) DMSO $\left(3.1 \times 10^{-5} \mathrm{M}\right)$ and (d) dichloromethane $\left(2.6 \times 10^{-5} \mathrm{M}\right)$.
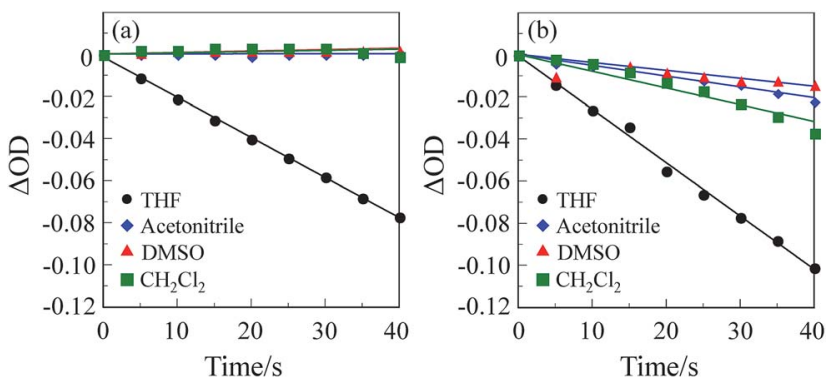

Fig. 6 Plots of $\triangle O D$ for DPBF against the photoirradiation time for the photooxidation of DPBF using (a) OEJ-1 and (b) OEJ-2 as photosensitizers under photoirradiation with $509 \mathrm{~nm}\left(160 \mu \mathrm{W} \mathrm{cm}{ }^{-2}\right)$ in THF, acetonitrile, DMSO and dichloromethane.

efficiency than OUJ-1 bearing $\mathrm{Br}^{-}$ion. Thus, the $\Phi_{\Delta}$ values of OEJ-1 and OEJ-2 were estimated by the relative method using Rose Bengal (RB) $\left(\Phi_{\Delta}=0.80\right)$ in methanol as the standard (Table 1). The $\Phi_{\Delta}$ value of OEJ-2 is $0.03,0.05,0.07$ and 0.22 in DMSO, acetonitrile, dichloromethane and THF, respectively, which is in good agreement with the $m_{\mathrm{sl}}$ value. A higher $\Phi_{\Delta}$ value in THF is ascribable to that as for the $(\mathrm{D}-\pi-)_{2} \mathrm{~A}$ pyrazinium dyes the ISC from ${ }^{1} \mathrm{~S}^{*}$ to the ${ }^{3} \mathrm{~S} *$ may be facilitated by THF, although further study for the solvent effects on ${ }^{1} \mathrm{O}_{2}$ generation is necessary to ensure the hypothesis. It is worth noting that the $\Phi_{\Delta}$ values of OEJ-2 in all the four solvents are higher than those of OEJ-1. Therefore, the high $\Phi_{\Delta}$ value of OEJ2 relative to $\mathbf{O E J}-\mathbf{1}$ is attributed to the fact that $\mathrm{I}^{-}$ion possesses superior heavy-atom effect rather than $\mathrm{Br}^{-}$ion, resulting in the facilitation of the ISC.
In order to evaluate the photosensitizing ability of the $(\mathrm{D}-\pi-)_{2} \mathrm{~A}$ pyrazinium dyes, the $\ln \left(C_{t} / C_{0}\right)$ is plotted against the photoirradiation time, where $C_{t}$ is a concentration of DPBF at the reaction time $(t)$ and $C_{0}$ is the initial concentration of DPBF before photoirradiation (Fig. 9). All the four solvents (THF, acetonitrile, DMSO and dichloromethane) were bubbled with air for $15 \mathrm{~min}$. The air-saturated solution containing the dye (OEJ-1 or OEJ-2) and DPBF was irradiated with visible light ( $>510$

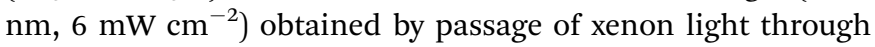
a $510 \mathrm{~nm}$ long path filter. The photoabsorption spectral changes for the photooxidation of DPBF using OEJ-1 and OEJ-2 under photoirradiation with the visible light in the four solvents are shown in Fig. 7 and 8 , respectively. The $\ln \left(C_{t} / C_{0}\right)$ decreased almost linearly with the increase in the photoirradiation time, although the linear relationship for the $\ln \left(C_{t} / C_{0}\right)$ for OEJ-2 in dichloromethane become steeper after the photoirradiation for 5 min under this photoirradiation. Thus, this result indicates the $\ln \left(C_{t} / C_{0}\right)$ bears a linear relationship with the photoirradiation time to provide the first-order rate constants $\left(K_{\text {obs }}\right)$ for the photooxidation of DPBF using OEJ-1 and OEJ-2 as the photosensitizer (Table 1). The $K_{\text {obs }}$ values for $\mathbf{O E J - 2}$ are greater than those of OEJ-1, although the $K_{\text {obs }}$ value for OEJ-2 in THF is lower than that of OEJ-1 due to the low photoabsorption property of OEJ-2 in THF. Interestingly, the plot of OEJ-2 in dichloromethane show a non-linear relationship, but the slope for OEJ-2 become steeper after 5 min of photoirradiation and the $K_{\text {obs }}$ value for OEJ-2 in dichloromethane is greater than those in the other solvents. This interesting observation may be attributed to not only the bathochromic shift and broadening of absorption but also the enhancement of heavy-atom effect with the increase in the photoirradiation time in dichloromethane, that is, the significant specific solvatochromic behavior of the
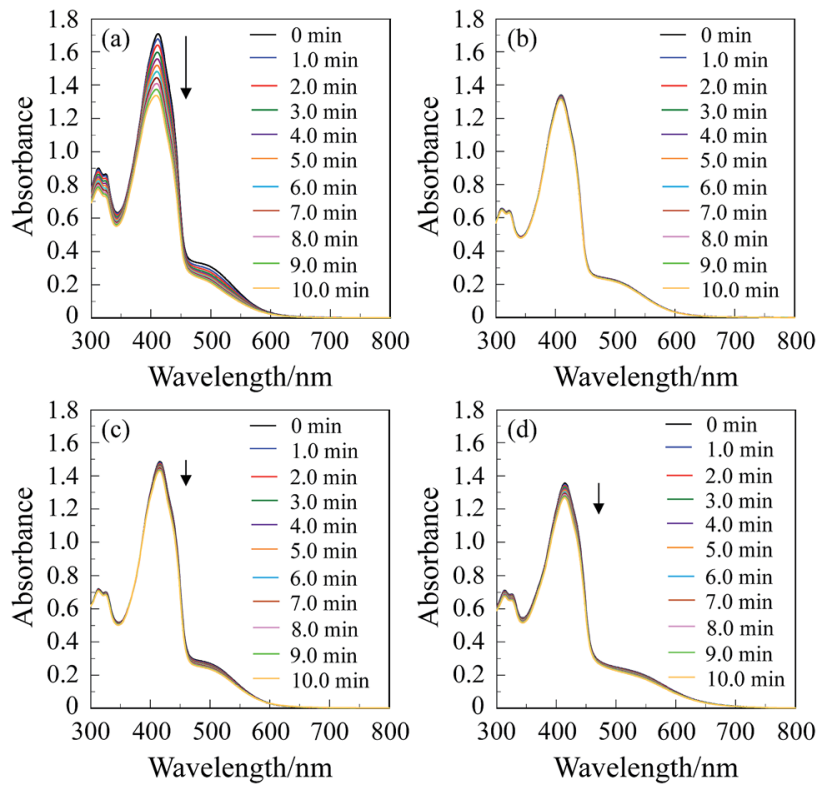

Fig. 7 Photoabsorption spectral changes for the photooxidation of $\operatorname{DPBF}\left(5.0 \times 10^{-5} \mathrm{M}\right)$ using OEJ-1 $\left(1.0 \times 10^{-5} \mathrm{M}\right)$ as photosensitizer under photoirradiation with visible light ( $>510 \mathrm{~nm}, 6 \mathrm{~mW} \mathrm{~cm}^{-2}$ ) in (a) THF, (b) acetonitrile, (c) DMSO and (d) dichloromethane. 

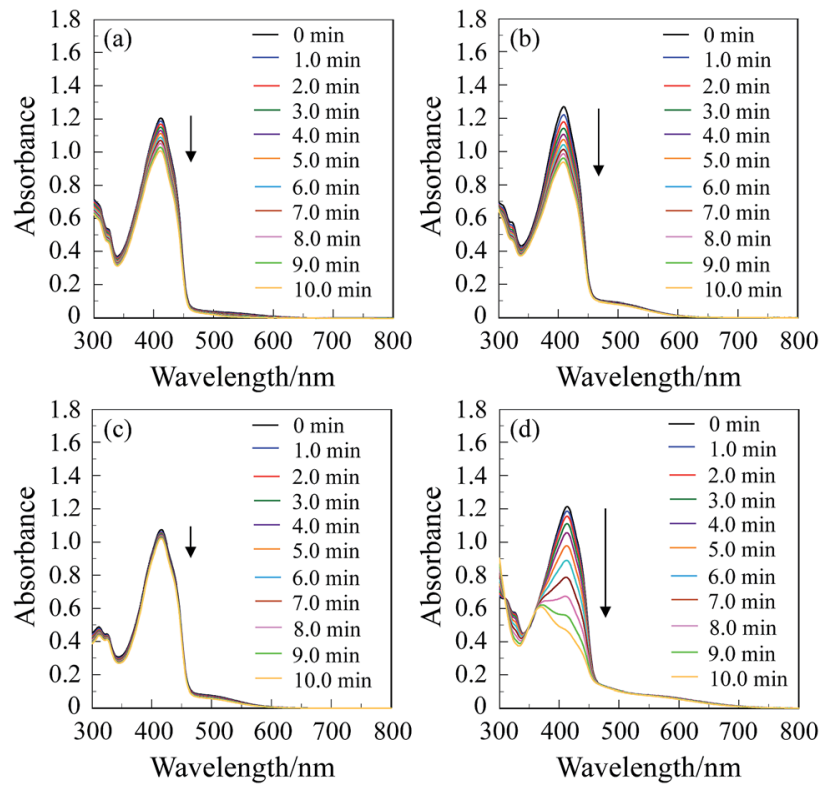

Fig. 8 Photoabsorption spectral changes for the photooxidation of $\operatorname{DPBF}\left(5.0 \times 10^{-5} \mathrm{M}\right)$ using OEJ-2 $\left(1.0 \times 10^{-5} \mathrm{M}\right)$ as photosensitizer under photoirradiation with visible light ( $>510 \mathrm{~nm}, 6 \mathrm{~mW} \mathrm{~cm}{ }^{-2}$ ) in (a) THF, (b) acetonitrile, (c) DMSO and (d) dichloromethane.
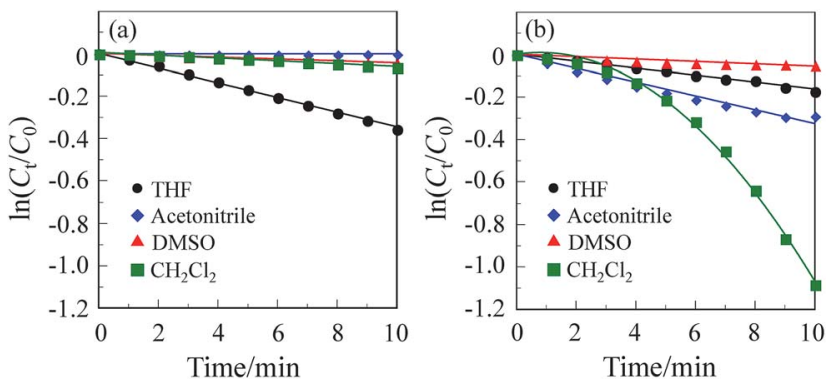

Fig. 9 Plots of $\ln \left(C_{t} / C_{0}\right)$ for DPBF against the photoirradiation time for the photooxidation of DPBF using (a) OEJ-1 and (b) OEJ-2 as photosensitizers under photoirradiation with visible light $(>510 \mathrm{~nm}, 6 \mathrm{~mW}$ $\mathrm{cm}^{-2}$ ) in THF, acetonitrile, DMSO and dichloromethane.

$(\mathrm{D}-\pi-)_{2}$ A pyrazinium dye bearing $\mathrm{I}^{-}$ion. Therefore, this result demonstrates that OEJ-2 exhibits more efficient photosensitizing ability compared to $\mathbf{O E J - 1}$, due to a superior heavy-atom effect of $\mathrm{I}^{-}$ion.

In addition, we performed an electron paramagnetic resonance (EPR) method with 2,2,6,6-tetramethyl-4-piperidone (4oxo-TEMP) as the spin-trapping agent, which can react with ${ }^{1} \mathrm{O}_{2}$ to produce 4-oxo-TEMPO as a stable nitroxide radical. ${ }^{14,23}$ When the air-saturated solution containing OEJ-2 and 4-oxo-TEMP was irradiated with visible light $\left(>510 \mathrm{~nm}, 14 \mathrm{~mW} \mathrm{~cm}^{-2}\right)$ obtained by passage of xenon light through a $510 \mathrm{~nm}$ long path filter, the ESR spectrum of 4-oxo-TEMPO was clearly observed as a characteristic 1:1:1 triplet (Fig. S6 $\dagger$ ). Moreover, to obtain the direct evidence of ${ }^{1} \mathrm{O}_{2}$ generation by $(\mathrm{D}-\pi-)_{2} \mathrm{~A}$ pyrazinium dyes, a phosphorescence spectrum of ${ }^{1} \mathrm{O}_{2}$ was measured in airsaturated THF solution of OEJ-2. The phosphorescence maximum of ${ }^{1} \mathrm{O}_{2}$ produced upon the excitation of OEJ-2 at $467 \mathrm{~nm}$ was clearly observed at around $1270 \mathrm{~nm}$ (Fig. S7 $\dagger)^{6 \boldsymbol{6}, \mathbf{1 4 , 2 4}}$ Consequently, this work demonstrated that $(\mathrm{D}-\pi-)_{2} \mathrm{~A}$ pyrazinium dyes possess the ability to generate ${ }^{1} \mathrm{O}_{2}$ under visible light irradiation.

\section{Conclusions}

$(\mathrm{D}-\pi-)_{2} \mathrm{~A}$ pyrazinium dyes bearing a counter anion $\left(\mathrm{X}^{-}=\mathrm{Br}^{-}\right.$or $\left.\mathrm{I}^{-}\right)$which show specific solvatochromic behavior leading to the bathochromic shift of photoabsorption band in halogenated solvents, have been designed and developed as a photosensitizer possessing singlet oxygen $\left({ }^{1} \mathrm{O}_{2}\right)$ generation. This work demonstrated that the $(\mathrm{D}-\pi-)_{2} \mathrm{~A}$ pyrazinium dyes possess the ability to generate ${ }^{1} \mathrm{O}_{2}$ under visible light irradiation, due to the effective intersystem crossing (ISC) from the singlet excited state of the photosensitizer $\left({ }^{1} \mathrm{~S}^{*}\right)$ to the triplet excited state $\left({ }^{3} \mathrm{~S}^{*}\right)$ by the heavy-atom effect of the counter anion. It was found that the ${ }^{1} \mathrm{O}_{2}$ quantum yield $\left(\Phi_{\Delta}\right)$ of OEJ-2 bearing $\mathrm{I}^{-}$ion is higher than that of OEJ-1 bearing $\mathrm{Br}^{-}$ion. Consequently, this result indicates that the high $\Phi_{\Delta}$ value of $\mathbf{O E J}-2$ relative to $\mathbf{O E J}-1$ is attributed to the fact that $\mathrm{I}^{-}$ion possesses superior heavy-atom effect rather than $\mathrm{Br}^{-}$ion, resulting in the facilitation of the ISC. Moreover, it was found that THF is a favorable solvent for the $(\mathrm{D}-\pi-)_{2} \mathrm{~A}$ pyrazinium dyes to provide higher $\Phi_{\Delta}$ value compared with the polar solvents such as acetonitrile and DMSO. Thus, this result suggests that as for $(\mathrm{D}-\pi-)_{2} \mathrm{~A}$ pyrazinium the ISC from ${ }^{1} S^{*}$ to the ${ }^{3} S^{*}$ may be facilitated by THF, although much effort for the solvent effects on ${ }^{1} \mathrm{O}_{2}$ generation is necessary to ensure the hypothesis. Interestingly, the first-order rate constants $\left(K_{\text {obs }}\right)$ for the photooxidation of DPBF using OEJ-2 in dichloromethane is greater than those in the other solvents, which is attributed to the bathochromic shift and broadening of absorption in dichloromethane, that is, the significant specific solvatochromic behavior of the $(\mathrm{D}-\pi-)_{2} \mathrm{~A}$ pyrazinium dye bearing $\mathrm{I}^{-}$ion. Further study to gain greater insight into the effects of the molecular structure of pyrazinium dyes on the ${ }^{1} \mathrm{O}_{2}$ generation efficiency is now in progress by developing the $(\mathrm{D}-\pi-)_{2} \mathrm{~A}$ pyrazinium photosensitizers possessing strong photoabsorption property in body therapeutic window (650$900 \mathrm{~nm}$ ) and water solubility.

\section{Experimental}

\section{General}

Melting points were measured with a Yanaco micro melting point apparatus MP model. IR spectra were recorded on a SHIMADZU IRAffinity-1 spectrometer by ATR method. Highresolution mass spectral data were acquired on a Thermo Fisher Scientific LTQ Orbitrap XL. ${ }^{1} \mathrm{H}$ NMR spectra were recorded on a Varian-400 (400 MHz) FT NMR spectrometer. Photoabsorption spectra were observed with a HITACHI U-2910 spectrophotometer. Cyclic voltammetry (CV) curves were recorded in and acetonitrile $/ \mathrm{Bu}_{4} \mathrm{NClO}_{4}(0.1 \mathrm{M})$ solution with a three-electrode system consisting of $\mathrm{Ag} / \mathrm{Ag}^{+}$as reference electrode, Pt plate as working electrode, and Pt wire as counter 
electrode by using a Electrochemical Measurement System HZ7000 (HOKUTO DENKO).

\section{Synthesis}

1-Butyl-3,5-bis(5-(9-butyl-7-(diphenylamino)-9H-carbazol-2yl)thiophen-2-yl)pyrazin-1-ium bromide (OEJ-1). A solution of OUK-2 (ref. 19) (0.15 g, $0.15 \mathrm{mmol}$ ) and 1-bromobutane (1.28 g, $9.4 \mathrm{mmol})$ in DMF $(8 \mathrm{ml})$ was stirred at $80^{\circ} \mathrm{C}$ for 5 days under an argon atmosphere. After concentrating under reduced pressure, the resulting residue was subjected to reprecipitation from dichloromethane-hexane. The reprecipitation solid was chromatographed on reverse-phase silica gel (chloroform-methanol $=1: 3$ as eluent) to give OEJ-1 (0.078 g, yield $46 \%)$ as dark red solids; mp $152-153{ }^{\circ} \mathrm{C}$; IR (ATR): $\tilde{\nu}=1624,1591,1526,1487$, 1445, $1427 \mathrm{~cm}^{-1} ;{ }^{1} \mathrm{H}$ NMR (400 MHz, DMSO-d $\left.{ }_{6}\right) \delta=0.83(\mathrm{t}, J=$ $7.4 \mathrm{~Hz}, 6 \mathrm{H}), 1.01(\mathrm{t}, J=7.5 \mathrm{~Hz}, 3 \mathrm{H}), 1.19-1.26(\mathrm{~m}, 4 \mathrm{H}), 1.46-1.52$ $(\mathrm{m}, 2 \mathrm{H}), 1.65-1.73(\mathrm{~m}, 4 \mathrm{H}), 2.07-2.14(\mathrm{~m}, 2 \mathrm{H}), 4.35(\mathrm{t}, J=7.0 \mathrm{~Hz}$, $4 \mathrm{H}), 4.58(\mathrm{t}, J=7.3 \mathrm{~Hz}, 2 \mathrm{H}), 6.89(\mathrm{dd}, J=1.8$ and $8.4 \mathrm{~Hz}, 2 \mathrm{H})$, 7.04-7.09 (m, 12H), 7.18 (d, $J=1.7 \mathrm{~Hz}, 2 \mathrm{H}), 7.31-7.36(\mathrm{~m}, 8 \mathrm{H})$, $7.66(\mathrm{dd}, J=1.5$ and $8.3 \mathrm{~Hz}, 2 \mathrm{H}), 7.98(\mathrm{~d}, J=4.0 \mathrm{~Hz}, 2 \mathrm{H}), 8.06(\mathrm{~s}$, $2 \mathrm{H}), 8.10(\mathrm{~d}, J=8.4 \mathrm{~Hz}, 2 \mathrm{H}), 8.16(\mathrm{~d}, J=8.1 \mathrm{~Hz}, 2 \mathrm{H}), 8.25(\mathrm{~d}, J=$ $4.0 \mathrm{~Hz}, 2 \mathrm{H}), 9.51(\mathrm{~s}, 2 \mathrm{H}) \mathrm{ppm} ;{ }^{13} \mathrm{C}$ NMR $\left(100 \mathrm{MHz}, \mathrm{DMSO}_{6}\right) \delta=$ 13.49 , 13.71, 19.06, 19.75, 30.68, 32.23, 34.40, 41.80, 104.80, 106.26, 116.73, 117.48, 117.68, 120.58, 121.62, 122.90, 123.03, 123.59, 123.71, 129.38, 129.50, 136.45, 140.89, 140.95, 142.12, 146.34, 147.57, 147.63, 151.89, 152.04 ppm; HRMS (ESI): $m / z$ (\%): calcd for $\mathrm{C}_{72} \mathrm{H}_{65} \mathrm{~N}_{6} \mathrm{~S}_{2}{ }^{+} 1077.47066$; found 1077.47144 .

1-Butyl-3,5-bis(5-(9-butyl-7-(diphenylamino)-9H-carbazol-2yl)thiophen-2-yl)pyrazin-1-ium iodide (OEJ-2). A solution of OUK-2 (ref. 19) (0.045 g, $0.04 \mathrm{mmol})$ and 1-iodobutane $(0.81 \mathrm{~g}$, $4.4 \mathrm{mmol}$ ) in DMF ( $3 \mathrm{ml})$ was stirred at $80^{\circ} \mathrm{C}$ for 3 days under an argon atmosphere. After concentrating under reduced pressure, the resulting residue was subjected to reprecipitation from dichloromethane-hexane to give OEJ-2 (0.042 g, yield 77\%) as dark red solids; mp 227-228 ${ }^{\circ} \mathrm{C}$; IR (ATR): $\tilde{\nu}=1624,1591,1528$, 1487, 1445, $1425 \mathrm{~cm}^{-1} ;{ }^{1} \mathrm{H}$ NMR (400 MHz, DMSO-d $\left.{ }_{6}\right) \delta=0.83$ $(\mathrm{t}, J=7.5 \mathrm{~Hz}, 6 \mathrm{H}), 1.01(\mathrm{t}, J=7.4 \mathrm{~Hz}, 3 \mathrm{H}), 1.18-1.27(\mathrm{~m}, 4 \mathrm{H})$, 1.44-1.52 (m, 2H), 1.65-1.73 (m, 4H), 2.06-2.14 (m, 2H), 4.35 (t, J $=7.0 \mathrm{~Hz}, 4 \mathrm{H}), 4.58(\mathrm{t}, J=7.7 \mathrm{~Hz}, 2 \mathrm{H}), 6.89(\mathrm{dd}, J=1.8$ and 8.4 $\mathrm{Hz}, 2 \mathrm{H}), 7.04-7.09(\mathrm{~m}, 12 \mathrm{H}), 7.18(\mathrm{~d}, J=1.7 \mathrm{~Hz}, 2 \mathrm{H}), 7.31-7.36$ $(\mathrm{m}, 8 \mathrm{H}), 7.66(\mathrm{dd}, J=1.4$ and $8.1 \mathrm{~Hz}, 2 \mathrm{H}), 7.98(\mathrm{~d}, J=4.0 \mathrm{~Hz}$, $2 \mathrm{H}), 8.06(\mathrm{~s}, 2 \mathrm{H}), 8.10(\mathrm{~d}, J=8.4 \mathrm{~Hz}, 2 \mathrm{H}), 8.16(\mathrm{~d}, J=8.2 \mathrm{~Hz}, 2 \mathrm{H})$, $8.25(\mathrm{~d}, J=4.0 \mathrm{~Hz}, 2 \mathrm{H}), 9.50(\mathrm{~s}, 2 \mathrm{H}) \mathrm{ppm} ;{ }^{13} \mathrm{C}$ NMR $(100 \mathrm{MHz}$, DMSO-d $\left.{ }_{6}\right) \delta=13.49,13.71,19.06,19.75,30.69,32.22,41.79$, $104.81,106.28,116.75,117.50,117.68,120.59,121.61,122.89$, 123.04, 123.69, 129.31, 129.37, 129.50, 136.43, 140.89, 142.12, 146.33, 147.56, 151.90, $152.06 \mathrm{ppm}$ (one aliphatic and two aromatic carbon signals were not observed owing to overlapping resonances); HRMS (ESI): $m / z$ (\%): calcd for $\mathrm{C}_{72} \mathrm{H}_{65} \mathrm{~N}_{6} \mathrm{~S}_{2}{ }^{+}$1077.47066; found 1077.47131.

\section{Evaluation of ${ }^{1} \mathrm{O}_{2}$ quantum yield}

Quantum yields $\left(\Phi_{\Delta}\right)$ for singlet oxygen $\left({ }^{1} \mathrm{O}_{2}\right)$ generation by (D$\pi-)_{2} \mathrm{~A}$ pyrazinium dyes (OEJ-1 and $\left.\mathbf{O E J}-2\right)$ in various solvents (THF, acetonitrile, DMSO and dichloromethane) were evaluated by monitoring the photoabsorption spectral change of the known ${ }^{1} \mathrm{O}_{2} \quad$ scavenger 1,3 -diphenylisobenzofuran (DPBF) accompanied by the reaction of DPBF with the generated ${ }^{1} \mathrm{O}_{2}$, that is, DPBF can trap ${ }^{1} \mathrm{O}_{2}$ through its photooxidation. All the solvents were bubbled with air for $15 \mathrm{~min}$. The absorbance of DPBF was adjusted to around 1.0 in air-saturated solvent. Concentration of OEJ-1 or OEJ-2 was adjusted with an absorbance of $0.2-0.3$ at the irradiation wavelength $(509 \mathrm{~nm})$. The airsaturated solution containing the photosensitizer (OEJ-1 or OEJ2) and DPBF was irradiated with $509 \mathrm{~nm}\left(160 \mu \mathrm{W} \mathrm{cm} \mathrm{cm}^{-2}\right)$ obtained by passage of xenon light through monochromator. The photoabsorption spectral change of DPBF with the photoirradiation was monitored with an interval of $5 \mathrm{~s}$ up to $40 \mathrm{~s}$. The absorption band of DPBF at around $410 \mathrm{~nm}$ decreased with the increase in the photoirradiation time. The changes in optical density $(\triangle \mathrm{OD})$ of DPBF are plotted against the photoirradiation time, and the slope is used to estimate the $\Phi_{\Delta}$ of OEJ-1 and OEJ2. The $\Phi_{\Delta}$ of $\mathbf{O E J - 1}$ and $\mathbf{O E J}-2$ was estimated by the relative method using Rose Bengal $(\mathrm{RB})\left(\Phi_{\Delta}=0.80\right)$ in methanol as the standard. Therefore, the ${ }^{1} \Phi_{\Delta}$ values were calculated according to the following eqn (1):

$$
\Phi_{\Delta \mathrm{sam}}=\Phi_{\Delta \mathrm{ref}} \times\left[\left(m_{\mathrm{sam}} / m_{\mathrm{ref}}\right) \times\left(L_{\mathrm{ref}} / L_{\mathrm{sam}}\right)\right]
$$

where $\Phi_{\Delta \text { sam }}$ and $\Phi_{\Delta \text { ref }}$ are the ${ }^{1} \mathrm{O}_{2}$ quantum yield of photosensitizer (OEJ-1 or OEJ-2) and RB, respectively, $m_{\text {sam }}$ and $m_{\text {ref }}$ are the slope of the difference $(\Delta \mathrm{OD})$ in the change in the absorption maximum wavelength of DPBF (around $410 \mathrm{~nm}$ ) which are plotted against the photoirradiation time, $L_{\text {sam }}$ and $L_{\text {ref }}$ are the light harvesting efficiency, which is given by $L=1-10^{-A}$ (" $A$ " is the absorbance at the photoirradiation wavelength).

\section{Photosensitizing ability}

Photosensitizing ability of the $(\mathrm{D}-\pi-)_{2} \mathrm{~A}$ pyrazinium dyes (OEJ-1 and OEJ-2) in various solvents (THF, acetonitrile, DMSO and dichloromethane) was evaluated by plotting the $\ln \left(C_{t} / C_{0}\right)$ against the photoirradiation time, where $C_{t}$ is a concentration of DPBF at the reaction time $(t)$ and $C_{0}$ is the initial concentration of DPBF before photoirradiation. All the solvents were bubbled with air for $15 \mathrm{~min}$. The air-saturated solution containing the photosensitizer $\left(1 \times 10^{-5} \mathrm{M}\right.$ for OEJ-1 and OEJ-2, $1 \times 10^{-6} \mathrm{M}$ for $\mathrm{RB})$ and DPBF $\left(5 \times 10^{-5} \mathrm{M}\right)$ was irradiated with visible light (>510 $\mathrm{nm}, 6 \mathrm{~mW} \mathrm{~cm}^{-2}$ ) obtained by passage of xenon light through a $510 \mathrm{~nm}$ long path filter. The absorbance of DPBF was adjusted to around 1.0 in air-saturated solvent. The photooxidation of DPBF with the photoirradiation was monitored by following the decrease in the photoabsorption at around 410 $\mathrm{nm}$ with an interval of $20 \mathrm{~s}$ up to $10 \mathrm{~min}$. The concentration $\left(C_{t}\right)$ of DPBF at the reaction time $(t)$ was calculated based on Lambert-Beer law $\left(A_{\mathrm{DPBF}}=\varepsilon c l\right)$. The $\ln \left(C_{t} / C_{0}\right)$ decreased almost linearly with the increase in the photoirradiation time due to the photooxidation of DPBF, that is, the slope was used to estimate the rate constants $\left(K_{\mathrm{obs}}\right)$.

\section{${ }^{1} \mathrm{O}_{2}$ detection by EPR spin-trapping method with 4-oxo-TEMP}

The EPR spectra were recorded on a JEOL JES-RE1X spectrometer under the following experimental conditions: temperature 
$298 \mathrm{~K}$, microwave power $1 \mathrm{~mW}$, microwave frequency $9.439 \mathrm{GHz}$, field modulation $0.2 \mathrm{mT}$ at $100 \mathrm{kHz}$, and scan time 4 min. The air-saturated THF solution containing OEJ-2 $(0.01 \mathrm{mM})$ as the photosensitizer and 4-oxo-TEMP $(50 \mathrm{mM})$ as the spin-trapping agent was irradiated with visible light $(>510$ $\mathrm{nm}, 14 \mathrm{~mW} \mathrm{~cm}^{-2}$ for $30 \mathrm{~min}$ ) obtained by passage of xenon light through a $510 \mathrm{~nm}$ long path filter. The ESR spectrum of 4-oxoTEMPO which is formed by the reaction of 4-oxo-TEMP with ${ }^{1} \mathrm{O}_{2}$, was clearly observed as a characteristic 1:1:1 triplet (Fig. S6†).

\section{Phosphorescence measurement of ${ }^{1} \mathrm{O}_{2}$}

Phosphorescence spectrum of ${ }^{1} \mathrm{O}_{2}$ was recorded on a HORIBA NanoLog spectrometer equipped with a $450 \mathrm{~W}$ xenon lamp and a photomultiplier tube (NIR-PMT R5509-43 liquid nitrogen configurations, Hamamatsu photonics). The phosphorescence maximum of ${ }^{1} \mathrm{O}_{2}$ produced upon the excitation of OEJ-2 (0.07 $\mathrm{mM}$ THF solution) at $467 \mathrm{~nm}$ was clearly observed at around 1270 nm (Fig. S7†).

\section{Acknowledgements}

This work was supported by Grants-in-Aid for Scientific Research (B) from the Japan Society for the Promotion of Science (JSPS) KAKENHI Grant Number $15 \mathrm{H} 03859$ and by Electric Technology Research Foundation of Chugoku. We would also like to thank Dr Yasushi Nakata of HORIBA, Ltd. for support with phosphorescence measurement of singlet oxygen.

\section{References}

1 J. F. Lovell, T. W. B. Liu, J. Chen and G. Zheng, Chem. Rev., 2010, 110, 2839.

2 M. C. DeRosa and R. J. Crutchley, Coord. Chem. Rev., 2002, 233-234, 351.

3 M. Pawlicki, H. A. Collins, R. G. Denning and H. L. Anderson, Angew. Chem., Int. Ed., 2009, 48, 3244; Angew. Chem., 2009, 121, 3292.

4 K. A. Leonard, M. I. Nelen, L. T. Anderson, S. L. Gibson, R. Hilf and M. R. Detty, J. Med. Chem., 1999, 42, 3942.

5 F. Ronzani, A. Trivella, E. Arzoumanian, S. Blanc, M. Sarakha, C. Richard, E. Oliveros and S. Lecombe, Photochem. Photobiol. Sci., 2013, 12, 2160.

6 (a) R. Schmidt and E. Afshari, J. Phys. Chem., 1990, 94, 4377; (b) M. Mirenda, C. A. Strassert, L. E. Dicelio and E. S. Román, ACS Appl. Mater. Interfaces, 2010, 2, 1556.

7 (a) J. P. Belair, C. J. Ziegler, C. S. Rajesh and D. A. Modarelli, J. Phys. Chem. A, 2002, 106, 6445; (b) P. C. Lo, J. D. Huang, D. Y. Y. Cheng, E. Y. M. Chan, W. P. Fong, W. H. Ko and D. K. P. Ng, Chem.-Eur. J., 2004, 10, 4831; (c) A. Karotki, M. Khurana, J. R. Lepock and B. C. Wilson, Photochem. Photobiol., 2006, 82, 443; (d) L. Delanaye, M. A. Bahri, F. Tfibel, M.-P. Fontaine-Aupart, A. Mouithys-Mickalad, B. Heine, J. Piette and M. Hoebeke, Photochem. Photobiol. Sci., 2006, 5, 317; (e) M. Morone, L. Beverina, A. Abbotto, F. Silvestri, E. Collini, C. Ferrante, R. Bozio and
G. A. Pagani, Org. Lett., 2006, 8, 2719; $(f)$ M. Khurana, H. A. Collins, A. Karotki, H. L. Anderson, D. T. Cramb and B. C. Wilson, Photochem. Photobiol., 2007, 84, 1441.

8 (a) A. P. Thomas, P. S. S. Babu, S. A. Nair, S. Ramakrishnan, D. Ramaiah, T. K. Chandrashekar, A. Srinivasan and M. R. Pillai, J. Med. Chem., 2012, 55, 5110; (b) K. Hirakawa, Y. Nishimura, T. Arai and S. Okazaki, J. Phys. Chem. B, 2013, 117, 13490; (c) H. Horiuchi, M. Hosaka, H. Mashio, M. Terata, S. Ishida, S. Kyushin, T. Okutsu, T. Takeuchi and H. Hiratsuka, Chem.-Eur. J., 2014, 20, 6054; (d) Q. Yu, E. M. Rodriguez, R. Naccache, P. Forgione, G. Lamoureux, F. Sanz-Rodriguez, D. Scheglman and J. A. Capobianco, Chem. Commun., 2014, 50, 12150; (e) D. Yao, V. Hugues, M. Blanchard-Desce, O. Mongin, C. O. Paul-Roth and F. Paul, New J. Chem., 2015, 39, 7730; (f) J. Schmitt, V. Heitz, A. Sour, F. Bolze, H. Ftouni, J.-F. Nicoud, L. Flamigni and B. Ventura, Angew. Chem., Int. Ed., 2015, 54, 169; Angew. Chem., 2015, 127, 171.

9 (a) X. J. Jiang, P. C. Lo, Y. M. Tsang, S. L. Yeung, W. P. Fong and D. K. P. Ng, Chem.-Eur. J., 2010, 16, 4777; (b) M. R. Ke, S. L. Yeung, W. P. Fong, D. K. P. Ng and P. C. Lo, Chem.Eur. J., 2012, 18, 4225; (c) A. R. Karimi and A. Khodadadi, Tetrahedron Lett., 2012, 53, 5223; (d) S. G. Kimani, T. A. Shmigol, S. Hammond, J. B. Phillips, J. I. Bruce, A. J. MacRobert, M. V. Malakhov and J. P. Golding, Photochem. Photobiol., 2013, 89, 139.

10 (a) A. Gorman, J. Killoran, C. O'Shea, T. Kenna, W. M. Gallagher and D. F. O'Shea, J. Am. Chem. Soc., 2004, 126, 10619; (b) T. Yogo, Y. Urano, Y. Ishitsuka, F. Maniwaa and T. Nagano, J. Am. Chem. Soc., 2005, 127, 12162; (c) S. O. McDonnell, M. J. Hall, L. T. Allen, A. Byrne, W. M. Gallagher and D. F. O'Shea, J. Am. Chem. Soc., 2005, 127, 16360; (d) M. J. Hall, L. T. Allen and D. F. O'Shea, Org. Biomol. Chem., 2006, 4, 776; (e) J. Killoran and D. F. O'Shea, Chem. Commun., 2006, 1503.

11 (a) N. Adarsh, R. R. Avirah and D. Ramaiah, Org. Lett., 2010, 12, 5720; (b) Y. Cakmak, S. Kolemen, S. Duman, Y. Dede, Y. Dolen, B. Kilic, Z. Kostereli, L. T. Yildirim, A. L. Dogan, D. Guc and E. U. Akkaya, Angew. Chem., Int. Ed., 2011, 50, 11937; Angew. Chem., 2011, 123, 12143; (c) S. G. Awuah, J. Polreis, V. Biradar and Y. You, Org. Lett., 2011, 13, 3884; (d) N. Adarsh, M. Shanmugasundaram, R. R. Avirah and D. Ramaiah, Chem.-Eur. J., 2012, 18, 12655.

12 (a) Y. C. Yang, Q. L. Guo, H. C. Chen, Z. K. Zhou, Z. J. Guo and Z. Shen, Chem. Commun., 2013, 49, 3940; (b) W. Li, L. Li, H. Xiao, R. Qi, Y. Huang, Z. Xie, X. Jing and H. Zhang, RSC Adv., 2013, 3, 13417; (c) L. Huang, X. Cui, B. Therrien and J. Zhao, Chem.-Eur. J., 2013, 19, 17472; (d) G. Awuah, S. K. Das, F. D'Souza and Y. You, Chem.-Asian J., 2013, 8, 3123; (e) S. Guo, L. Ma, J. Zhao, B. Küçüköz, A. Karatay, M. Hayvali, H. G. Yaglioglu and A. Elmali, Chem. Sci., 2014, 5, 489; (f) Y.-C. Lai and C.-C. Chang, J. Mater. Chem. C, 2014, 2, 1576; $(g)$ R. L. Watley, S. G. Awuah, M. Bio, R. Cantu, H. B. Gobeze, V. N. Nesterov, S. K. Das, F. D'Souza and Y. You, Chem.Asian J., 2015, 10, 1335. 
13 (a) J. W. Arbogast and C. S. Foote, J. Am. Chem. Soc., 1991, 113, 8886; (b) J. W. Arbogast, A. P. Darmanyan, C. S. Foote, F. N. Diederich, R. L. Whetten, Y. Rubin, M. M. Alvarez and S. J. Anz, J. Phys. Chem., 1991, 95, 11; (c) A. Ikeda, T. Sato, K. Kitamura, K. Nishiguchi, Y. Sasaki, J. Kikuchi, T. Ogawa, K. Yogo and T. Takeya, Org. Biomol. Chem., 2005, 3, 2907; (d) P. Mroz, G. P. Tegos, H. Gali, T. Wharton, T. Sarna and M. R. Hamblin, Photochem. Photobiol. Sci., 2007, 6, 1139.

14 Y. Yamakoshi, N. Umezawa, A. Ryu, K. Arakane, N. Miyata, Y. Goda, T. Masumizu and T. Nagano, J. Am. Chem. Soc., 2003, 125, 12803.

15 W. Wu, J. Sun, X. Cui and J. Zhao, J. Mater. Chem. C, 2013, 1, 4577.

16 (a) R. Gao, D. G. Ho, B. Hernandez, M. Selke, D. Murphy, P. I. Djurovich and M. E. Thompson, J. Am. Chem. Soc., 2002, 124, 14828; (b) P. I. Djurovich, D. Murphy, M. E. Thompson, B. Hernandez, R. Gao, P. L. Hunt and M. Selke, Dalton Trans., 2007, 3763; (c) S. Takizawa, R. Aboshi and S. Murata, Photochem. Photobiol. Sci., 2011, $10,895$.

17 (a) J. C. Koziar and D. O. Cowan, Acc. Chem. Res., 1978, 11, 334; (b) C. Schweitzer and R. Schmidt, Chem. Rev., 2003, 103, 1685.

18 (a) F. Ronzani, E. Arzoumanian, S. Blanc, P. Bordat, T. Pigot, C. Cugnet, E. Oliveros, M. Sarakha, C. Richard and S. Lacombe, Phys. Chem. Chem. Phys., 2013, 15, 17219; (b) D. Huand, J. Sun, L. Ma, C. Zhang and J. Zhao, Photochem. Photobiol. Sci., 2013, 12, 872; (c) S. Cobo, F. Lafolet, E. Saint-Aman, C. Philouze, C. Bucher, S. Silvi, A. Credi and G. Royal, Chem. Commun., 2015, 51, 13886.

19 Y. Ooyama, K. Uenaka, Y. Harima and J. Ohshita, RSC Adv., 2014, 4, 30225.

20 (a) Y. Ooyama, R. Asada, S. Inoue, I. Imae, K. Komaguchi and Y. Harima, New J. Chem., 2009, 33, 2311; (b) Y. Ooyama, K. Kushimoto, Y. Oda, D. Tokita, N. Yamaguchi, S. Inoue,
T. Nagano, Y. Harima and J. Ohshita, Tetrahedron, 2012, 68, 8577; (c) Y. Ooyama, Y. Oda, T. Mizumo and J. Ohshita, Tetrahedron, 2013, 69, 1755; (d) Y. Ooyama, Y. Oda, T. Mizumo, Y. Harima and J. Ohshita, Eur. J. Org. Chem., 2013, 4533.

21 Both the geometry optimization and energy calculation were performed by employing the density functional theory (DFT), at the level of B3LYP/6-31G(d,p) on the Gaussian09 program package (M. J. Frisch, G. W. Trucks, H. B. Schlegel, G. E. Scuseria, M. A. Robb, J. R. Cheeseman, G. Scalmani, V. Barone, B. Mennucci, G. A. Petersson, H. Nakatsuji, M. Caricato, X. Li, H. P. Hratchian, A. F. Izmaylov, J. Bloino, G. Zheng, J. L. Sonnenberg, M. Hada, M. Ehara, K. Toyota, R. Fukuda, J. Hasegawa, M. Ishida, T. Nakajima, Y. Honda, O. Kitao, H. Nakai, T. Vreven, J. A. Montgomery Jr, J. E. Peralta, F. Ogliaro, M. Bearpark, J. J. Heyd, E. Brothers, K. N. Kudin, V. N. Staroverov, R. Kobayashi, J. Normand, K. Raghavachari, A. Rendell, J. C. Burant, S. S. Iyengar, J. Tomasi, M. Cossi, N. Rega, J. M. Millam, M. Klene, J. E. Knox, J. B. Cross, V. Bakken, C. Adamo, J. Jaramillo, R. Gomperts, R. E. Stratmann, O. Yazyev, A. J. Austin, R. Cammi, C. Pomelli, J. W. Ochterski, R. L. Martin, K. Morokuma, V. G. Zakrzewski, G. A. Voth, P. Salvador, J. J. Dannenberg, S. Dapprich, A. D. Daniels, O. Farkas, J. B. Foresman, J. V. Ortiz, J. Cioslowski and D. J. Fox, Gaussian 09, Revision A.02, Gaussian, Inc., Wallingford CT, 2009).

22 K. Golinick and A. Griesbeck, Tetrahedron, 1985, 41, 2057.

23 S. Oriana, S. Aroua, J. O. B. Söllner, X.-J. Ma, Y. Iwamoto and Y. Yamakoshi, Chem. Commun., 2013, 49, 9302.

24 (a) H. Horiuchi, T. Kameya, M. Hosaka, K. Yoshimura, S. Kyushin, H. Matsumoto, T. Okutsu, T. Takeuchi and H. Hiratsuka, J. Photochem. Photobiol., A, 2011, 221, 98; (b)

K. Hirakawa, N. Fukunaga, Y. Nishimura, T. Arai and S. Okazaki, Bioorg. Med. Chem. Lett., 2013, 23, 2704. 